NOTICE: this is the author's version of a work that was accepted for publication in Electrochemistry Communications. Changes resulting from the publishing process, such as peer review, editing, corrections, structural formatting, and other quality control mechanisms may not be reflected in this document. Changes may have been made to this work since it was submitted for publication. A definitive version was subsequently published in Electrochemistry Communications, 13, 5, 2011. DOI 10.1016/j.elecom.2011.02.025 


\title{
Array of Water|Room Temperature Ionic Liquid Micro-Interfaces
}

\author{
Debbie S. Silvester, Damien W. M. Arrigan* \\ Nanochemistry Research Institute, Department of Chemistry, Curtin University, GPO Box U1987, Perth, 6845, \\ Australia. \\ *E-mail: d.arrigan@curtin.edu.au; Fax:+61(8)92664699; Tel:+61(8)92669735
}

\begin{abstract}
Cyclic Voltammetry and AC Voltammetry were used to characterise the micro-interface array between water and a commercially available room temperature ionic liquid (RTIL) trihexyltetradodecylphosphonium tris(pentafluoroethyl)trifluoromethylphosphate $\left(\left[\mathrm{P}_{14,6,6,6}\right][\mathrm{FAP}]\right)$ for the first time. The interface array was formed within the micropores of a silicon chip membrane (30 pores, $23 \mu \mathrm{m}$ diameter). The polarisable potential window and capacitance curves were recorded, and the transfers of three cations (tetraalkylammoniums) and three anions (tetraphenylborate, hexafluorophosphate and tetrafluoroborate) across the interface were studied. The shapes of the voltammograms revealed that the RTIL filled the pores and that the interface was located at/near the pore mouths. This is the first report of voltammetry at an array of water|RTIL microinterfaces, rather than at a single interface or porous polymer supported-interface. This work is particularly relevant to the sensing/extraction of redox-inactive ions.
\end{abstract}

\section{Keywords}

Room temperature ionic liquid, water/ionic liquid interface, ion transfer, voltammetry, microinterface. 


\section{Introduction}

Room Temperature Ionic Liquids (RTILs) are increasingly regarded as attractive electrochemical solvents, due to their intrinsic conductivity and wide electrochemical windows (often $\geq 5$ Volts) at solid|liquid interfaces. Several reviews on electrochemistry in ionic liquids at metal electrodes have been published [1-3], showing many reactions and mechanisms that are similar in RTILs and conventional solvents [2, 3], but several cases where the behaviour is very different [1]. In particular, the structure of the RTIL/metal electrode interface is not similar to conventional solvents (with supporting electrolyte) [4]. Advantages of using RTILs include: low volatility, high stability, wide electrochemical windows, intrinsic conductivity and the ability to dissolve a wide range of species. Drawbacks include high viscosity and high resistance. These problems can be reduced by using micron-sized electrodes/interfaces.

Recently, ion transfer at the water|room temperature ionic liquid (W|RTIL) interface has attracted increasing attention, since the first report by Quinn et al. [5]. In particular, the group of Kakiuchi has been very active [6-8] since their pioneering work in 2003 [9], and the first review paper on this topic was published recently [10]. Ion transfer at the W|RTIL interface is a special case of ion transfer at the interface between two immiscible electrolyte solutions (ITIES), which enables the study and detection of ions not easily oxidisable or reducible at solid|liquid interfaces. Conventional experiments are performed with a water phase in contact with an organic phase, usually 1,2-dichloroethane or nitrobenzene [11]. Most of the W|RTIL studies so far have focussed on very hydrophobic salts that are solid at room temperature, with a few recent reports of RTILs that are liquid at $25^{\circ} \mathrm{C}$ [8, 12]. The work reported so far has been performed at single interfaces of milli- [9, 12], micro- [7] or nano- [8] metre dimensions. RTILs have also been used in a solid-supported polyvinylidenefluoride membrane sandwiched between two aqueous phases [13].

In this work, we report the behaviour of a W|RTIL micro-interface array formed between water and the

RTIL trihexyltetradodecylphosphonium tris(pentafluoroethyl)trifluoromethylphosphate $\left(\left[\mathrm{P}_{14,6,6,6}\right][\mathrm{FAP}]\right)$ within a silicon micropore membrane (consisting of 30 micropores of ca. $23 \mu \mathrm{m}$ diameter). The micro-interface array provides the advantages of radial diffusion and larger currents than are obtained at a single micro-interface, which are advantageous in, e.g., sensor applications of ion 
transfer at W|RTIL interfaces. Here, the micro-interface array is characterised by cyclic voltammetry (CV) of some simple ion transfers and AC voltammetry.

\section{Experimental}

\subsection{Chemicals}

All chemicals were purchased from Sigma-Aldrich except the RTIL trihexyltetradodecylphosphonium tris(pentafluoroethyl)-trifluoromethylphosphate (Figure 1 inset, [ $\left.\mathrm{P}_{14,6,6,6}\right][\mathrm{FAP}]$ ) which was from Merck, in high purity grade. The salts used in ion-transfer experiments were tetraethylammonium $\left(\mathrm{TEA}^{+}\right.$) chloride, tetrapropylammonium (TPrA ${ }^{+}$) chloride, tetrabutylammonium (TBA ${ }^{+}$) bromide, sodium tetraphenylborate $\left(\mathrm{TPB}^{-}\right)$, potassium hexafluorophosphate $\left(\mathrm{PF}_{6}^{-}\right)$and potassium tetrafluoroborate $\left(\mathrm{BF}_{4}^{-}\right)$. Aqueous solutions were prepared with deionised water $(18 \mathrm{M} \Omega . \mathrm{cm})$ from a Milli Q water purification system (Millipore Pty Ltd, North Ryde, NSW, Australia).

\subsection{Silicon Microporous Membrane}

The microporous membrane used in this work was a $5 \mathrm{~mm} \times 5 \mathrm{~mm}$ silicon chip, prepared as previously described [14] by a combination of photolithography, wet etching and dry etching. The array consisted of 30 micropores, ca. $23 \mu \mathrm{m}$ in diameter, with $200 \mu \mathrm{m}$ spacing between pore centres (see Figure 1, inset) [15].

\subsection{Electrochemical Experiments}

All electrochemical experiments were preformed using an Autolab PGSTAT302N with NOVA or GPES software (Eco Chemie, Netherlands). A two-electrode cell was employed, with a Ag|AgCl wire placed in the aqueous phase $\left(10^{-2} \mathrm{M} \mathrm{LiCl}+0.5 \mathrm{mM}\right.$ of the appropriate salt, $\left.\mathrm{XY}\right)$ and a second $\mathrm{Ag} \mid \mathrm{AgCl}$ wire in an aqueous reference solution of the ionic liquid $\left(10^{-2} \mathrm{M} \mathrm{LiCl}+\right.$ saturated $\left.\left[\mathrm{P}_{14,6,6,6}\right] \mathrm{Cl}\right)$. The two aqueous phases were housed in borosilicate glass tubes of $4 \mathrm{~mm}$ o.d. and $2.5 \mathrm{~mm}$ i.d., which were glued (with silicone glue) to the silicon microporous chip and a Vycor frit, respectively. In this cell, there is a polarisable interface at the W|RTIL boundary, and a non-polarisable interface at the $\mathrm{W}_{\text {ref }} \mid \mathrm{RTIL}$ boundary (see Figure 1 for cell notation). The two glass tubes were inserted into 300 $\mu \mathrm{L}$ of the RTIL that was housed in a vial of $10 \mathrm{~mm}$ inner diameter (see Figure 1). The W and RTIL phases were mutually pre-saturated before each experiment. IR drop compensation was not employed. 


\section{Results and Discussion}

The ionic liquid chosen in this work $\left(\left[\mathrm{P}_{14,6,6,6}\right][\mathrm{FAP}]\right)$ is one that is liquid at room temperature and contains a hydrophobic cation and anion. One of the main advantages of this RTIL (over those used in other W|RTIL studies $[6,8,9,12,13])$ is that it is commercially available from Merck, making it accessible to all researchers. The [FAP] $]^{-}$anion is regarded by many researchers as the most hydrophobic of all commonly used RTIL anions, with electrochemical windows reported for [FAP] ${ }^{-}$ salts of up to $7.0 \mathrm{~V}$ at solid|liquid interfaces $[16]$. $\left[\mathrm{P}_{14,6,6,6}\right]^{+}$is also regarded as very hydrophobic, as it possesses long carbon chains. The viscosity of $\left[\mathrm{P}_{14,6,6,6}\right][\mathrm{FAP}]$ is $464 \mathrm{cP}$ at room temperature and its melting point is $<-50^{\circ} \mathrm{C}[1]$. However, in our experiments the viscosity may be slightly lower, since the RTIL phase is pre-saturated with the water phase prior to experiments and the "hydrophobic" RTIL does uptake water to some extent $[16,17]$. This is believed to be the first report of liquid|liquid electrochemistry using this RTIL, although we note the use of this RTIL as a droplet on a tertbutylferrocene-modified glassy carbon electrode for anion insertions [18].

\subsection{Electrochemical Window and Capacitance Curve}

Figure 2 shows a typical CV of the $\mathrm{W} \mid\left[\mathrm{P}_{14,6,6,6}\right][\mathrm{FAP}]$ interface. The width of the polarisable potential window (PPW) is approximately $0.4 \mathrm{~V}$, which is similar to that observed by the groups of Kakiuchi and Mirkin at milli- [9, 12], micro- [7] and nano- [8] metre interfaces. The window is not defined by oxidation or reduction of the electrolyte, but by the transfer of ions into the opposite phase. Although the [FAP]" anion is "hydrophobic" [16], the window is still limited by its transfer into the aqueous phase, as reported by Quentel et al. [19] at a W|[C $\left.\mathrm{C}_{6} \mathrm{mim}\right][\mathrm{FAP}]$ interface $\left(\left[\mathrm{C}_{6} \mathrm{mim}\right]^{+}=1\right.$-hexyl-3methylimidazolium). PPWs of salts with fluorinated tetraphenylborate anions have been reported to be as high as $0.8 \mathrm{~V}$ at $56^{\circ} \mathrm{C}$ [6], however, these salts are solid at room temperature. In Figure 2, the negative end of the potential window is most likely limited by the transfer of $\mathrm{Cl}^{-}$from W to RTIL. The shape of the $\mathrm{CV}$ is relatively flat and shows an available potential range (-0.05 to $-0.45 \mathrm{~V})$ where low background current is observed.

In order to obtain a capacitance/voltage curve for the W|RTIL interface, AC voltammetry at different phase angles $\left(0^{\circ}\right.$ and $\left.90^{\circ}\right)$ was performed. The amplitude of the applied sinusoidal voltage of the AC signal was $5 \mathrm{mV}$, with a frequency of $6 \mathrm{~Hz}$. The phase shift, impedance and capacitance were calculated at various potentials (at $1 \mathrm{mV}$ intervals) in the polarisable potential range (as described previously [20]). Figure 2 (inset) shows the interfacial capacitance measurements for the 
$\mathrm{W} \mid\left[\mathrm{P}_{14,6,6,6}\right][\mathrm{FAP}]$ interface, giving a capacitance minimum at ca. $-0.18 \mathrm{~V}$, which is within the region of low background current on the CV. It should be noted that the minimum capacitance does not necessarily correspond to the potential of zero charge (pzc) in ionic liquids, as the structure of the interfacial region is different to that in conventional electrolyte solutions [4].

\subsection{Ion-Transfer Voltammetry}

In order to fully characterise the micro-interface array, the transfers of a number of ions across the W|RTIL interface were studied by CV. Figure 3 shows typical CVs for the transfer of (a) three tetraalkylammonium cations and (b) three anions (tetraphenylborate, hexafluorophosphate and tetrafluoroborate). The cations were transferred from the water to the RTIL phase (Fig. 3a), resulting in a steady-state voltammogram on the forward sweep (towards more positive potentials) and a peakshaped voltammogram on the backward sweep. In Figure 3b, the shapes of the voltammograms are reversed, since an ion of opposite charge was transferred across the interface. It is possible that these asymmetric CVs were due to the difference in diffusion coefficients of the ion in the water and RTIL phases, as is well known for oxygen [2]. If the interface was inlaid on the RTIL side of the silicon membrane, steady-state behaviour for $\mathrm{TBA}^{+}$would be expected on the reverse scan at $1 \mathrm{mVs}^{-1}$, according to the inequality [21]:

$$
v<<\frac{R T D}{Z_{\mathrm{i}} F r^{2}}
$$

where $v$ is the scan rate, $R$ is the gas constant, $D$ is the diffusion coefficient (estimated as $\sim 5 \times 10^{-8} \mathrm{~cm}^{2} \mathrm{~s}^{-}$ ${ }^{1}$ in the water-saturated RTIL), $z_{\mathrm{i}}$ is the charge of the transferring species, $F$ is the Faraday constant, and $r$ is the radius of the pore. However, CVs at $1 \mathrm{mVs}^{-1}$ (not shown) were peak-shaped on the reverse scan. This behaviour suggests that the interface was located at/near the mouths of the micropores on the water side of the membrane (with the RTIL filling the pores), resulting in radial diffusion of the ion from the water phase and linear diffusion imposed by the pores from the RTIL phase (see inset sketches, Figure 3). This was not unexpected, since the micropore walls were coated with a hydrophobic polymer during the fabrication process. Similar voltammetry was reported at water|organic solvent [14] and water|organogel interfaces [22] patterned by these micropore array membranes.

The limiting current $\left(I_{\mathrm{lim}}\right)$ can be predicted based on the size of the interface: 


$$
I_{\lim }=n 4 z_{\mathrm{i}} \mathrm{FDCr}
$$

where $n$ is the number of pores and $C$ is the bulk concentration. If all 30 pores were filled, a current of $35 \mathrm{nA}$ was expected for $0.5 \mathrm{mM} \mathrm{TBA}^{+}\left(D=5.2 \times 10^{-6} \mathrm{~cm}^{2} \mathrm{~s}^{-1}\right.$ in water at $298 \mathrm{~K}$ [23]). This corresponds to

the $I_{\lim }$ values depicted in Figure 3, suggesting that most or all of the pores were filled and that the interface was stable and well-behaved. For all ions where a well-defined $I_{\text {lim }}$ was obtained, $I_{\text {lim }}$ was proportional to the bulk concentration of the ion in the aqueous phase (0.05 to $5 \mathrm{mM})$.

The order of transfer (formal potentials) of the ions in Figure 3 represents their expected hydrophilicity. The relatively narrow PPW of $0.4 \mathrm{~V}$ limited the range of ions that can be transferred across the interface. For example, the transfer of tetraethylammonium was not clearly seen on the forward sweep (Fig. 3a), and transfer wave for tetramethylammonium was outside the PPW (data not shown). However, as long as the analyte ion being studied transfers within the PPW, this approach can be used for the ion detection at W|RTIL interfaces. With the continued development of new RTILs, the prospects for more hydrophobic RTILs that give wider PPWs are promising.

\section{Conclusions}

The micro-arrayed interface between water and a commercially available RTIL has been established for the first time within a silicon micropore array and characterised by voltammetry. The available potential window of $0.4 \mathrm{~V}$ was relatively moderate, but ample for the transfer across the interface of a range of cations and anions using CV. The shapes of the CVs were steady-state on the forward and peak-shaped on the reverse, suggesting that the pores were filled with the RTIL and that the interface was located at/near the pore mouths. The behaviour highlighted here suggests these micro-interface arrays will be useful tools in the study of detection and extraction processes of ions at W|RTIL interfaces. The main advantage of employing RTILs over conventional organic solvents is that RTILs are non-volatile and therefore can be used in robust sensing devices with extended lifetimes.

\section{Acknowledgements}

We thank Curtin University for a Curtin Research Fellowship (D.S.S.), Tyndall National Institute, Ireland, for the gift of the microporous silicon membranes and Dr. Mickaël Rimboud (Curtin) for useful discussions. 


\section{References:}

[1] L.E. Barrosse-Antle, A.M. Bond, R.G. Compton, A.M. O'Mahony, E.I. Rogers, D.S. Silvester, Chem. Asian J. 5 (2010) 202-230.

[2] M.C. Buzzeo, R.G. Evans, R.G. Compton, ChemPhysChem 5 (2004) 1106-1120.

[3] D.S. Silvester, R.G. Compton, Z. Phys. Chem. 220 (2006) 1247-1274.

[4] M.V. Fedorov, A.A. Kornyshev, Electrochim. Acta 53 (2008) 6835-6840.

[5] B.M. Quinn, Z. Ding, R. Moulton, A.J. Bard, Langmuir 18 (2002) 1734-1742.

[6] N. Nishi, S. Imakura, T. Kakiuchi, Anal. Chem. 78 (2006) 2726-2731.

[7] N. Tsujioka, S. Imakura, N. Nishi, T. Kakiuchi, Anal. Sci. 22 (2006) 667-671.

[8] Y. Wang, T. Kakiuchi, Y. Yasui, M.V. Mirkin, J. Am. Chem. Soc. 132 (2010) 16945-16952.

[9] T. Kakiuchi, N. Tsujioka, Electrochem. Commun. 5 (2003) 253-256.

[10] Z. Samec, J. Langmaier, T. Kakiuchi, Pure Appl. Chem. 81 (2009) 1473-1488.

[11] Z. Samec, Pure Appl. Chem. 76 (2004) 2147-2180.

[12] T. Kakiuchi, Y. Yasui, Y. Kitazumi, N. Nishi, ChemPhysChem 11 (2010) 2912-2918.

[13] J. Langmaier, Z. Samec, Electrochem. Commun. 9 (2007) 2633-2638.

[14] R. Zazpe, C. Hibert, J. O'Brien, Y.H. Lanyon, D.W.M. Arrigan, Lab Chip 7 (2007) 1732-1737.

[15] G. Herzog, S. O'Sullivan, J.S. Ellis, D.W.M. Arrigan, Sens. Lett. 9 (2011) In press.

[16] N. Ignat'ev, U. Welz-Biermann, A. Kucheryna, G. Bissky, H. Willner, J. Fluorine Chem. 126 (2005) 1150-1159.

[17] A.M. O'Mahony, D.S. Silvester, L. Aldous, C. Hardacre, R.G. Compton, J. Chem. Eng. Data 53 (2008) 2884-2891.

[18] G. Shul, W. Adamiak, M. Opallo, Electrochem. Commun. 10 (2008) 1201-1204.

[19] F. Quentel, C. Elleouet, V. Mirceski, V.A. Hernandez, M. L'Her, M. Lovric, S. KomorskyLovric, F. Scholz, J. Electroanal. Chem. 611 (2007) 192-200.

[20] G. Herzog, W. Moujahid, J. Strutwolf, D.W.M. Arrigan, Analyst 134 (2009) 1608-1613.

[21] R.G. Compton, C.E. Banks, Understanding Voltammetry, $1^{\text {st }}$ Ed., World Scientific, Singapore, 2007.

[22] J. Strutwolf, M.D. Scanlon, D.W.M. Arrigan, Analyst 134 (2009) 148-158.

[23] V. Sladkov, V. Guillou, S. Peulon, M. L'Her, J. Electroanal. Chem. 573 (2004) 129-138. 
Figure 1. Diagram of the cell used for electrochemical experiments at W|RTIL interfaces. Also included are an optical micrograph of the silicon micropore array (30 pores, $23 \mu \mathrm{m}$ diameter, [14]) and the chemical structure of the RTIL used.

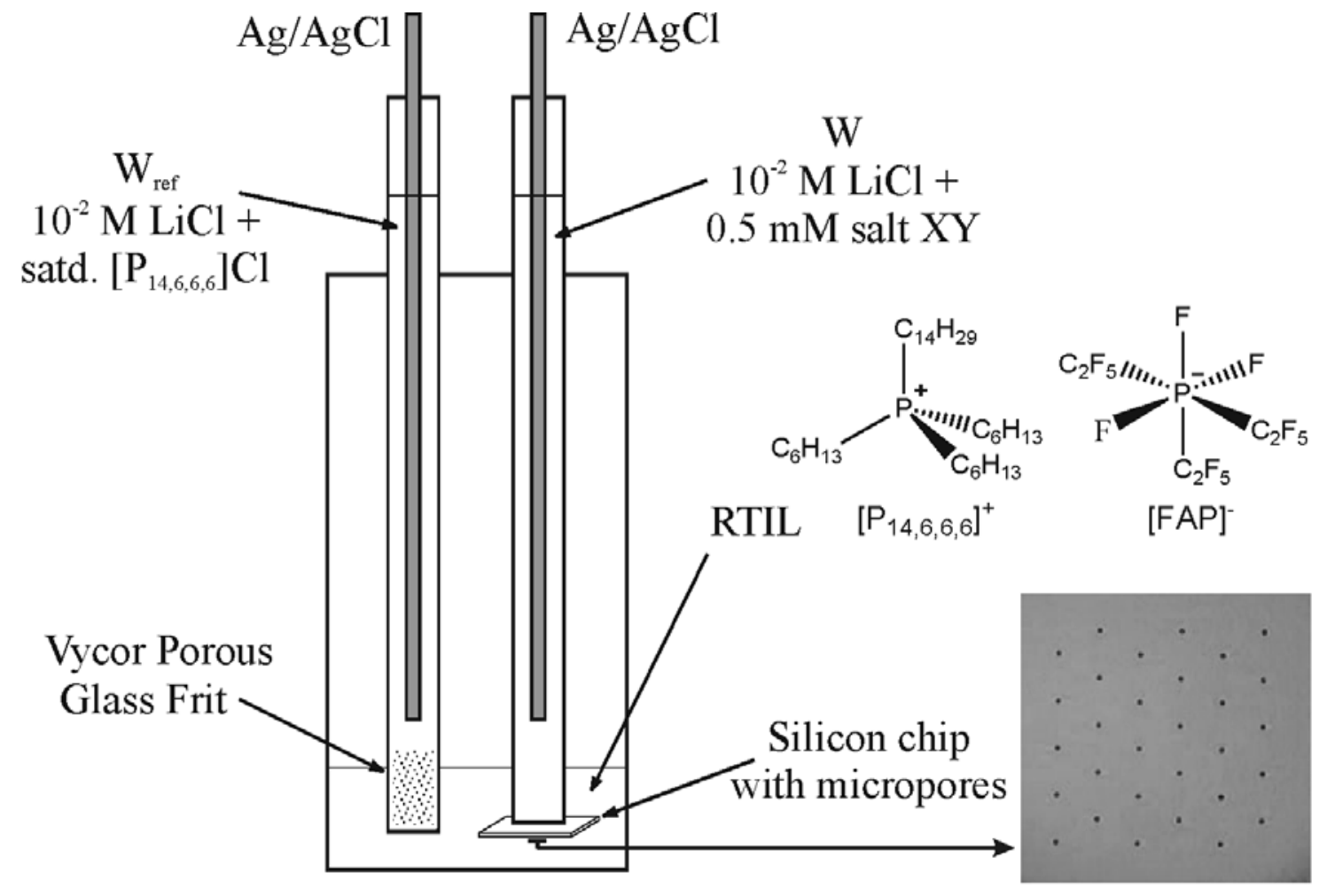

Electrochemical cell notation:

$\mathrm{Ag} / \mathrm{AgCl}\left|10^{-2} \mathrm{M} \mathrm{LiCl}+0.5 \mathrm{mM} \mathrm{XY}\right|\left|\left[\mathrm{P}_{14,6,6,6}\right][\mathrm{FAP}]\right|$

$$
10^{-2} \mathrm{M} \mathrm{LiCl}+\text { satd. }\left[\mathrm{P}_{14,6,6,6}\right] \mathrm{Cl} \mid \mathrm{AgCl} / \mathrm{Ag}
$$


Figure 2. $\mathrm{CV}$ at the interface between water $\left(10^{-2} \mathrm{M} \mathrm{LiCl}\right.$ background) and the RTIL $\left[\mathrm{P}_{14,6,6,6}\right][\mathrm{FAP}]$. Scan rate: $10 \mathrm{mVs}^{-1}$. The interface is patterned by an array of 30 pores (23 $\mu \mathrm{m}$ diameter) in a silicon membrane. Inset: the interfacial capacitance/voltage curve from AC voltammetry.

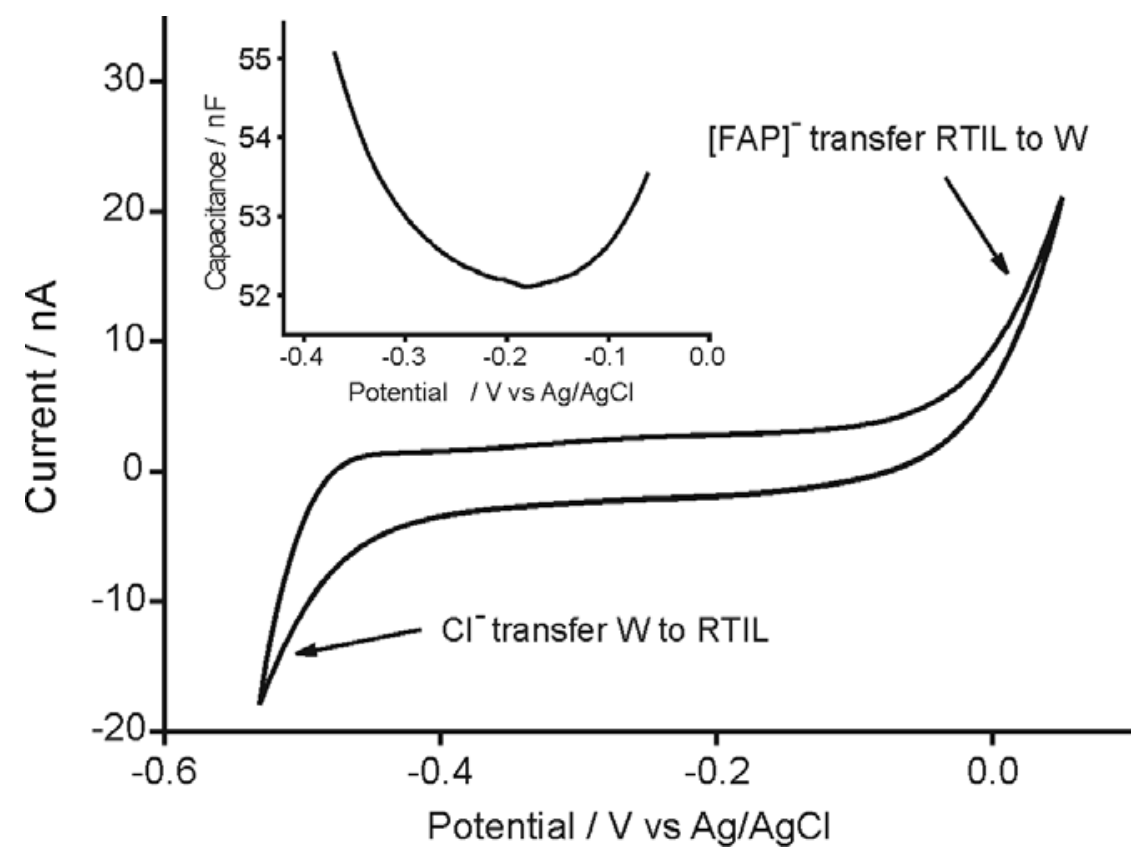


Figure 3. Ion-transfer voltammograms for the transfer of $0.5 \mathrm{mM}$ of (a) the cations tetrabutylammonium $\left(\mathrm{TBA}^{+}\right)$, tetrapropylammonium $\left(\mathrm{TPrA}^{+}\right)$and tetraethylammoniun $\left(\mathrm{TEA}^{+}\right)$, and (b) the anions tetraphenylborate $\left(\mathrm{TPB}^{-}\right)$, hexafluorophosphate $\left(\mathrm{PF}_{6}{ }^{-}\right)$and tetrafluoroborate $\left(\mathrm{BF}_{4}^{-}\right)$from water to the RTIL phase. Scan rate: $10 \mathrm{mVs}^{-1}$. Dotted line: $\mathrm{CV}$ shown in Figure 2. Insets: sketches of the predicted diffusion patterns giving rise to the observed voltammetry.
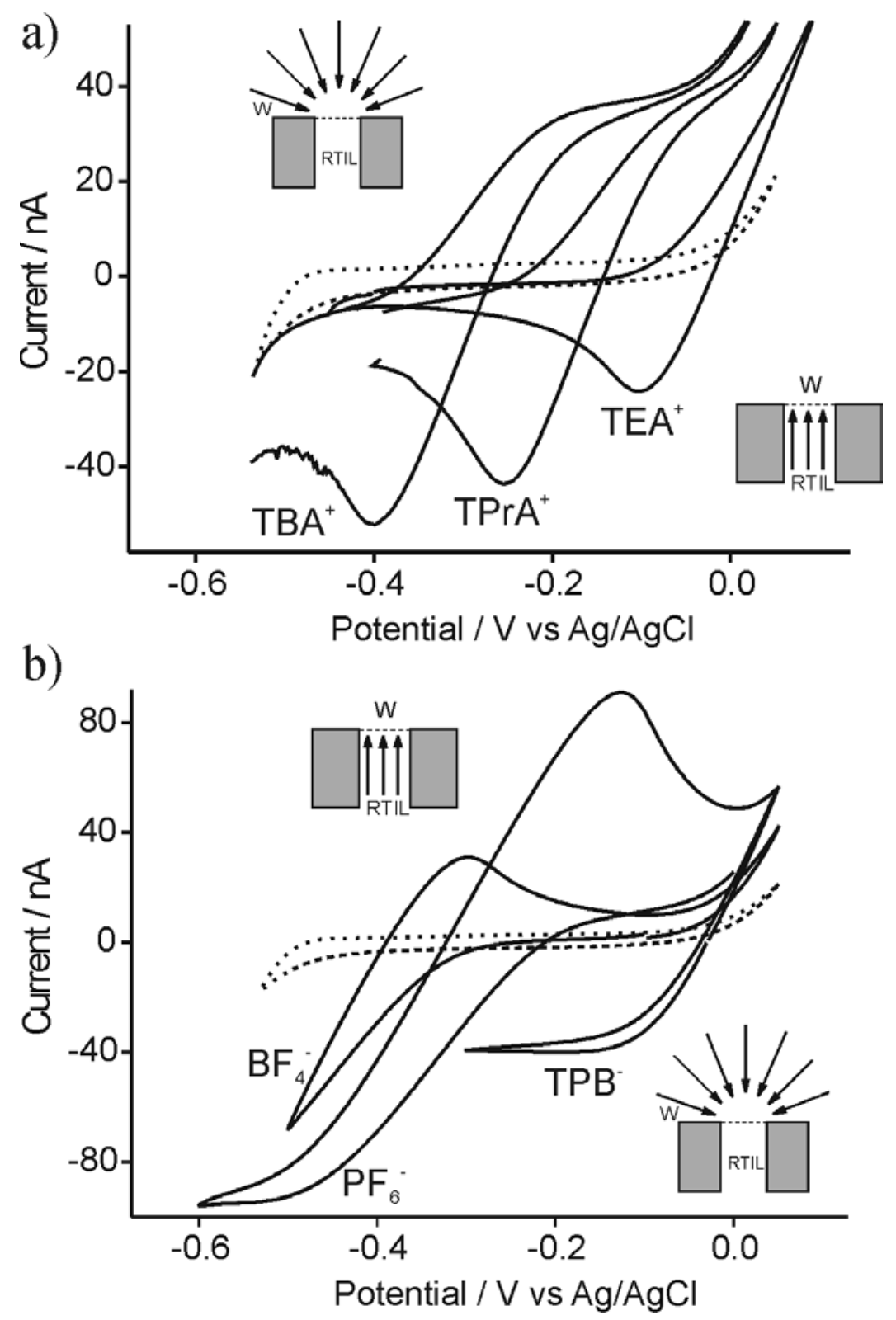